\title{
A multi-sensor approach for monitoring a road bridge in the Valencia harbor (SE Spain) by SAR Interferometry (InSAR)
}

\author{
Matteo Del Soldato $\left({ }^{\mathrm{a}, \mathrm{b}, \mathrm{c}}\right)$, Roberto Tomás $\left({ }^{\mathrm{c}}\right)$, Javier Pont $\left({ }^{\mathrm{c}}\right)$, Gerrardo Herrera $\left({ }^{\mathrm{d}}\right)$, \\ Juan Carlos García Lopez-Davalillos $\left({ }^{\mathrm{d}}\right)$ \& Oscar Mora $\left({ }^{\mathrm{e}}\right)$
}

\begin{abstract}
( $\left.{ }^{a}\right)$ Department of Earth Sciences, Environment and Resources, Federico II University of Napoli, Largo San Marcellino. E-mail: matteo.delsoldato@unina.it
( $)$ Department of Earth Sciences, University of Firenze, Via La Pira 4, 50121 Florence, Italy.

(c) Departamento de Ingeniería Civil, University of Alicante P.O. Box 99, E-03080 Alicante, Spain.

(d) Área de Investigación en Peligrosidad y Riesgos Geológicos, Departamento de Investigación y Prospectiva Geocientífica, Instituto Geológico y Minero de España (IGME), Ministerio de Ciencia y Tecnología, c/ Alenza 1, E-28003 Madrid, Spain.

$\left(^{\circ}\right)$ Altamira Information, c/ Còrsega 381-387, 08037 Barcelona, Spain.

Document type: Short note

Manuscript history: received 29 December 2015; received in revised form 26 February 2016; accepted 6 February 2016; editorial responsibility and handling by Lisa Borgatti
\end{abstract}

\section{ABSTRACT}

Settlement and angular distortion affecting the construction can cause damages on structures and they could compromise the serviceability of the structure. This work focuses on the monitoring of a bridge located on the south part of the Valencia harbor that shows some opening joints and depressions in the pavement of both transition areas between the abutments and the embankments. For this purpose Advanced Differential Interferometry is used to exploit Synthetic Aperture Radar images (SAR) acquired by ALOS and Cosmo-SkyMed satellite sensors from February 2007 to July 2010 and from May 2010 to August 2012, respectively. This approach permitted to estimate surficial displacements, to identify areas of bridge affected by settlements and angular distortion and to relate them with the observed damages.

KEY WORDS: angular distortion, bridge, harbor, PSInSAR, settlement

\section{INTRODUCTION}

Infrastructures built over the ground surface increase the effective stress level on soil causing soil consolidation. This effect is a well-known process by which soils decrease in volume causing ground-surface settlements. The monitoring of the displacements of infrastructures plays an essential role in its management and operation, especially for detecting unsafe conditions and problems, which require appropriate corrective measures at early stages. Among the different types of infrastructures, bridges are very sensitive to settlements. The settlement of a bridge is interpreted as the decreasing of the structure over an established level or the request by the structure of further measure respect the original design (Moulton, 1985). These settlements are usually limited by technical regulations (e.g. Eurocode) and then, a detailed and accurate monitoring along time is required.

Synthetic Aperture Radar Interferometry (InSAR) is a powerful technique for detecting and monitoring slow deformation with low costs over wide areas (Ferretti et al., 2001; Arnaud et al., 2003). This technique has been successfully used for monitoring landslides, active tectonism, volcanism, subsidence, seismic events and glacier dynamics (e.g. Massonet
\& Feigl, 1998; Ferretti et al., 2001; Farina et al., 2007). The use of high resolution SAR images (e.g. from TerraSAR-X or CosmoSkyMed) has also allowed the application of InSAR techniques to the monitoring of infrastructures (e.g. Herrera et al., 2010; Tomàs et al., 2014; Bianchini et al., 2015). This technique provides the displacements of the Persistent Scatterers (PS) of the scene, which are typically man-made structures or natural elements, with stable and strong back-scattering signal, e.g. in urbanized area.

In this work, a Persistent Scatterers Interferometric (PSI) technique (Ferretti et al., 2000) is applied to evaluate the settlement occurred in a reinforced concrete road structure of the Valencia harbor between 2007 and 2012. To this aim, a multisensor approach, using images of the constellations ALOS (Advanced Lands Observation Satellite) of the Japanese Aerospace Exploration Agency and COSMO-SkyMed (COnstellation of small Satellites for Mediterranean basin Observation) of the Italian Space Agency (ASI), has been adopted. The study was conducted in a Geographical Information System (GIS) environment, analyzing the settlement and the angular distortion affecting the structures for the intervals comprised from February 2007 to July 2010, ALOS sensor, and from May 2010 to August 2012, Cosmo-SkyMed (CSK) sensor. For this idea a similar methodology to that proposed by Sanabria et al. (2014) was followed.

\section{THE HARBOR AND THE INVESTIGATED SITE}

The city of Valencia is placed on the east coast of Spain. During the construction and the development of the Valencia harbor some morphological variations in the occupied territory were performed. As example, the Turia River, that originally crossed the Valencia city, was deviated. Complementarily, the migration of the bed of the river over centuries influenced the geotechnical characteristics of the materials involved. The area presents a flat topography and the underlying materials mainly consist on fine fluvial sediments with a high deformability.

The studied road viaduct is placed on the south entry of the harbor of Valencia. It is a concrete structure about $350 \mathrm{~m}$ long 
with three lanes in each direction that was built in 2004 above the railway, to improve the connection with the south part of the harbor of Valencia. The bridge is an overpass $12 \mathrm{~m}$ high sustained by the abutments and two lines of eleven pair of pillars with Y shape (fig. 1). The abutments consist on reinforced earth walls made of precast concrete facing panels. The pillars of the bridge were founded on a deep level of gravel by means of piles since the strata above did not guaranteed enough resistance.

According to the geotechnical studies performed on this area the stratigraphy, from the top, is constituted by:

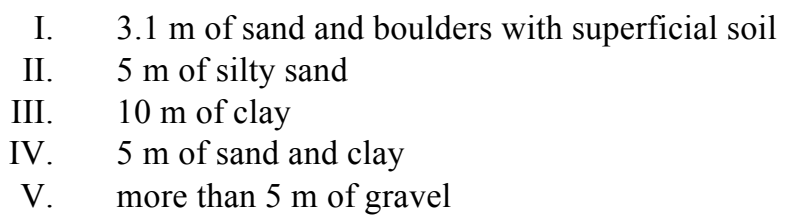

The performed geotechnical report indicates that the heterogeneity and the low thickness of the first level did not reach the needed resistance to use shallow foundations. The second level of sand could not guarantee the necessary strength for the foundations. The layers III and IV, despite their thickness, were not able to sustain the load transmitted by the pillars, requiring a more competent level. Finally, the piles that constituted the foundation of the pillars were embedded on the level $\mathrm{V}$ constituted by gravel.

The main problems related to the differential settlements are observable in the transition areas between the structure of the bridge and the abutment. As previously mentioned, at both ends of the bridge, the first meters of the filling behind the abutments were executed with reinforced earth to improve the behavior against settlements. From this height, about $12 \mathrm{~m}$, to ground surface level the reinforced earth wall is substituted by an earth embankment. The filling of the wall and the embankment is made of high quality earth that was compacted up to a unit weight of $24 \mathrm{kN} / \mathrm{m}^{3}$. To reduce the post-constructive settlement caused by the structure, a preload was placed on the ground surface for six months.

The structure was inspected in 2014 and some minor damage related with settlements (i.e. opening of the joints of some concrete precast facing panels of the reinforced earth walls and settlements on the pavement) were recognized in the transition areas between the bridge and the embankments.

\section{USED DATA AND RESULTS}

To monitor the displacement of the area and the settlement affecting the studied structures the Stable Point Network (SPN) algorithm (Arnaud et al., 2003; Duro et al., 2005) developed by Altamira Information was applied. The SPN technique belongs to the Persistent Scatterer Interferometry techniques (PSI). PSI relies on man-made or natural stable targets called PS (Persistent Scatterers) which show a dominant reflection component in the radar signal, while their scattering characteristics and coherence remain unchanged in time (Ferretti et al., 2001). PSI technique provides the annual velocities and the time series of displacement on a dense grid of PS benchmarks on the ground.

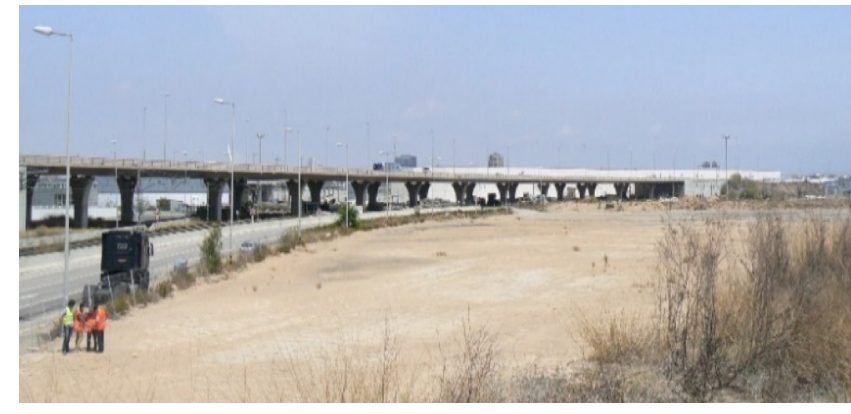

Fig. 1 - General view of the investigated bridge structure.

For more information on PSI applications see (Tomás et al., 2014).

The processing was conducted using 15 ascending ALOS images (L band) for a period comprised from $12^{\text {th }}$ February 2007 to 08th July 2010 and 54 descending CSK images (X band) for the interval comprised from $14^{\text {th }}$ May 2011 to $08^{\text {th }}$ August 2012. The ALOS images had an average temporal baseline of 88 days and a spatial resolution of $3.5 \times 4.7 \mathrm{~m}$, and the CSK images had 8 days of average temporal baseline with a ground spatial resolution of $2 \times 1 \mathrm{~m}$.

In fig. $2 a$ and fig. $2 b$ the PS of ALOS and CSK with a chromatic scale from blue to red are shown. The colors reflect a classification based on values of settlement: cold colors, from dark blue to green, indicate the reduction of the displacement toward the satellite sensor (i.e. uplift); hot colors, from green to red, indicate an increasing distance from the sensor (i.e. subsidence); the green color $( \pm 1.5 \mathrm{~mm})$ expresses the stable areas.

Fig. $2 \mathrm{c}$ and fig. $2 \mathrm{~d}$ show a longitudinal section traced on the middle of the viaduct from the bottom of both embankments to extract the settlement for the whole structures. Firstly, the PS were interpolated by a spatial regression to product two deformation maps of both investigated intervals (i.e. those corresponding to ALOS and CSK images). Secondly, after transforming the displacement into meters, the angular distortion was calculated as the tangent of the slope of the displacement. Subsequently, for both angular distortions and settlements, assessed separately for the ALOS and CSK sensors, the profiles along the section passed in the middle of the bridge and the location of the joints were plotted on the graphs shown in fig. $2 \mathrm{c}$ and $2 \mathrm{~d}$.

In this paper the attention is paid on some observed opened joints of the reinforced earth wall and the surface settlements recognized on the pavement of the studied bridge located on the south entry of the harbor of Valencia. The occurred displacements were monitored using a multi-sensor InSAR approach to understand the reason of damages. To this aim, the investigated area was divided into three zones: the bridge in the strict sense and the two transition regions (i.e. abutmentembankment), northern and southern.

InSAR data show a higher concentration of settlements in the transition areas between the structure and the embankments. In these regions the maximum settlements are $29.25 \mathrm{~mm}$ and 5.56 $\mathrm{mm}$ for the north area, and $40.45 \mathrm{~mm}$ and $4.93 \mathrm{~mm}$ for the south 

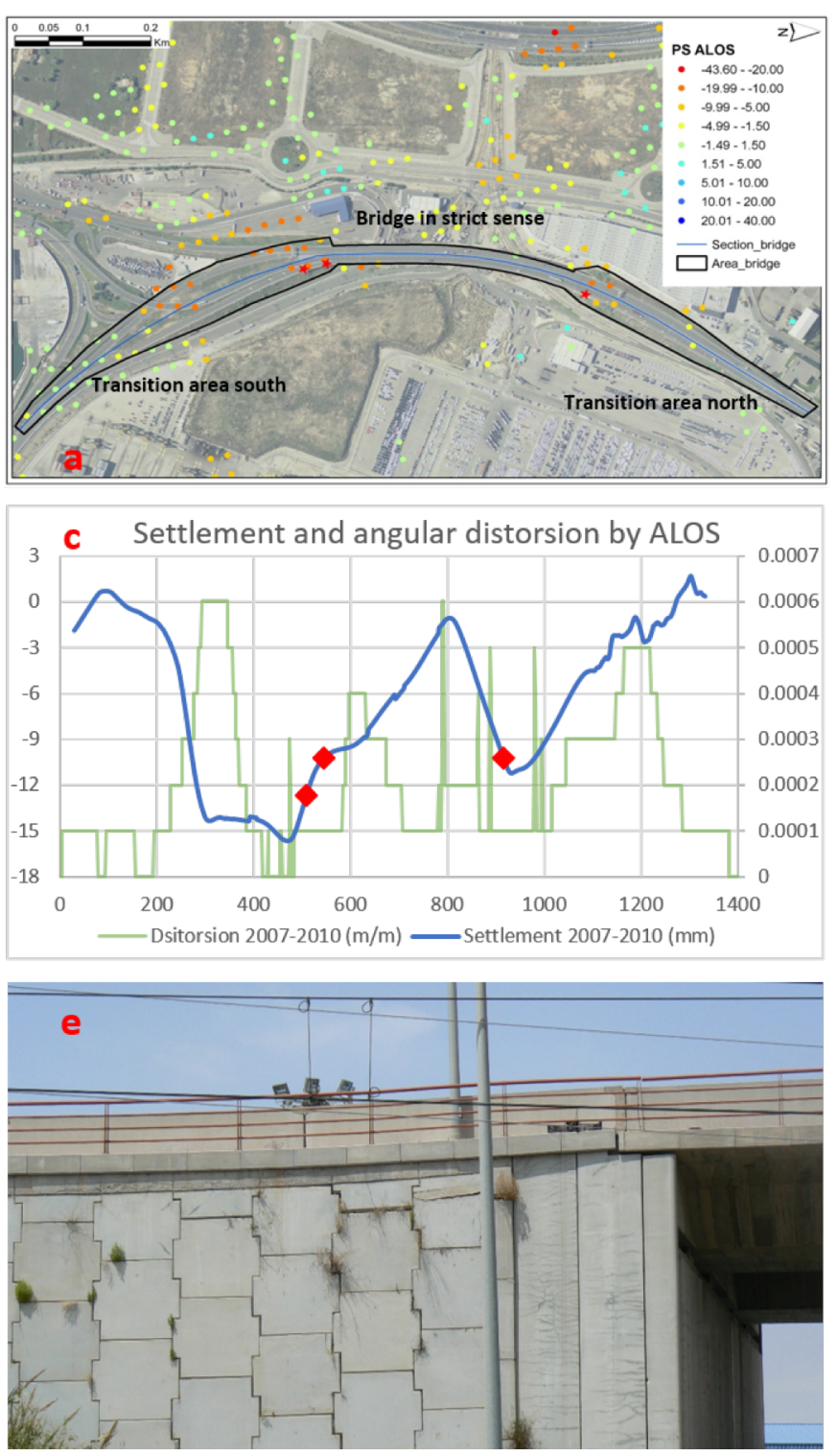


Fig. 2 - PS ALOS (a) and CSK (b) in a chromatic scale in the investigated area, divided in three zones, that shown the settlement (mm) affecting the structure in the periods 2007-2010 and 2011-2012, respectively. Note that the subsidence bowl located on the east of the structure corresponds to a preload (c) and (d). Longitudinal profiles of settlements and angular distortion along the section located in the middle axis of the bridge. The red points in (c) and (d) and the starts in (a) and (b) highlight the areas where the joints of the precast concrete facing panels are open in the north (e) and south (f) sides.

side for C- and L- bands, respectively. These settlements, derived from InSAR, were used for the later calculation of angular distortions.

The computed angular distortion affecting the study area was classified according to the different allowable limits defined by: a) Zhang et al. (2005) as allowable values; b) through a probabilistic approach based on several reported research studies by Jones et al. (2008) as a tolerable; and by Moulton (1985) and AASHTO (2012) as a limiting angular distortion. The performed analysis shows that the angular distortion results are under the limits for the entire structure, but with values slightly over the safety limit, in the areas comprised between the abutment of the bridge and the embankment, probably due to different settlement causing the damages on the road pavement. This is in accordance with the limits proposed by some authors in the literature (e.g. Zhang et al., 2005), which indicate that every case of study is different since the limiting tolerable displacement is depending of many factors, e.g. the type and dimension of the structures and foundations and the properties of subsurface soil.

It is important to highlight that the location of the main opened joint (fig. 2e and 2f), plotted in fig. $2 \mathrm{c}$ and $2 \mathrm{~d}$, are in correspondence with important variation of angular distortion above the reinforced earth wall from the abutment of the bridge, while the bridge, in strict sense, do not show problems. These facts are very clear in the south side of the bridge, but less evident in the north part. This discrepancy may be due to the few density of PS, only 34 , for the period covered by the ALOS images, against the 410 points for the interval with the CSK images. Furthermore, it must be taken into account that the 
higher displacements occurred immediately after the construction of the structure, before InSAR monitoring was possible. It means that the monitored settlements correspond to an advanced phase of the consolidation process (i.e. a high consolidation degree has been already reached).

The Asaoka's method (1978), an "observation procedure" based on the one-dimensional consolidation equation to predict the future primary consolidation settlement trough the past observations, has been also applied for both transition areas confirming the previous discussion. The results provided by this method indicate that the PS of CSK (covered period 2011-2012) are in accordance with the hypothesis that the settlement is close to the end and most of the consolidation occurred previously to the monitored interval. This could be the reason why there are some discrepancies between the location of the opened joints on the precast concrete facing panels of the reinforced earth wall and the computed angular distortion.

\section{ACKNOWLEDGMENTS}

This project was developed in the framework of the DORIS project (ground deformation risk scenarios: an advanced assessment service) funded by the EC-GMES-FP7 initiative (grant agreement 423 no. 242212) and by the Spanish Ministry of Economy and Competitiveness (MINECO) and EU FEDER, under project TIN2014-55413- C2-2-P. ALOS PALSAR images were provided by the project JAXA- 1209. The authors thank the University of Florence for founding Matteo Del Soldato for the PhD abroad period of research to the Department of Civil Engineering of the University of Alicante and the Autoridad Portuaria de Valencia for its kindly support.

\section{REFERENCES}

AASHTO (2012) - AASHTO LRFD Bridge Design Specification, $6^{\text {th }}$ Edition, Washington, D.C.: American Association of State Highway and Transportation Official.

Arnaud A., Adam N., Hanssen R., Inglada J., Duro J., Closa J. \& Eineder M. (2003) - ASAR ERS interferometric phase continuity. In: Geoscience and remote sensing symposium, 2003. IGARSS '03. Proceedings. 2003 IEEE International, 21-25 July 2003, 1132, 1133-1135.

Asaoka A. (1978) - Observational procedure of settlement prediction. Soils Found., 18(4), 87-101.
Bianchini S., Pratesi F., Nolesini T. \& Casagli N. (2015) Building Deformation Assessment by Means of Persistent Scatterer Interferometry Analysis on a Landslide-Affected Area: The Volterra (Italy) Case Study. Remote Sensing, 7(4), 4678-4701.

Duro J., Inglada J., Closa J., Adam N. \& Arnaud A. (2005) High resolution differential interferometry using time series of ERS and ENVI- SAT SAR data. In: FRINGE 2003, Frascati, Italy, 1-5 December.

Farina P., Casagli N. \& Ferretti A. (2007) - Radar-interpretation of InSAR measurements for landslide investigations in civil protection practices. In: First North American Landslide Conference, 272-283.

Ferretti A., Prati C. \& Rocca F. (2000) - Nonlinear subsidence rate estimation using permanent scatterers in differential SAR interferometry. IEEE T. Geosci. Remote, 38(5), 22022212.

Ferretti A., Prati C. \& Rocca, F. (2001) - Permanent scatterers in SAR interferometry. IEEE T. Geosci. Remote, 39(1), 820.

Herrera G., Tomás R., Monells D., Centolanza G., Mallorquí J.J., Vicente F., Navarro V.D., Lopez-Sanchez J.M., Sanabria M., Cano M. \& Mulas J. (2010) - Analysis of subsidence using TerraSAR-X data: Murcia case study. Eng. Geol., 116(3), 284-295.

Jones C.A., Stewart D.I. \& Danilewicz C.J. (2008) - Bridge distress caused by approach embankment settlement. Geotechnical Engineering, 161(2), 63-74.

Massonet D. \& Feigl K.L. (1998) - Radar interferometry and its applications to changes in Earth's surface. Rev. Geophys., 36(4), 441-500.

Moulton, L. K. (1985) - Tolerable movement criteria for highway bridges, Report No. FHWA/RD-85/107. Washington, DC: Federal Highway Administration.

Sanabria, M. P., Guardiola-Albert, C., Tomás, R., Herrera, G., Prieto, A., Sánchez, H., \& Tessitore, S. (2014) - Subsidence activity maps derived from DInSAR data: Orihuela case study. Nat. Hazards Earth Syst. Sci., 14(5), 1341.

Tomàs R., Romero R., Mulas. J., Marturià J.J., Mallorquì J.J., Lopez-Sanche J.M., Herrera G., Gutiérrez P.J., Fernàndez J., Duque S., Concha-Dimas A., Cocksley G., Castñeda C., Carrasco D. \& Blanco P. (2014). Radar interferometry techniques for the study of ground subsidence phenomena: a review of practical issue through cases in Spain. Environmental Earth Sciences, 71, 163-181.

Zhang L.M. \& Ng A.M.Y. (2005) - Probabilistic limiting tolerable displacements for serviceability limit state design of foundations. Geotechnique, 55(2), 151-161. 